\title{
Methodology and theory in a rural ECD research project: Capturing Mogwase in 'becoming'
}

\begin{abstract}
Conducting research on early education development at rural sites in South Africa is challenging. This is partly because it is difficult to capture the vast array of factors that impact on the lives of people in rural communities. In this article the author reports on some of the difficulties, showing how cultural historical and activity theory (CHAT) can be used as a lens in a participatory action research (PAR) project. The author argues that far from being a negative by-product of development, tension, if managed effectively, could be harnessed as a powerful driving force of change and transformation. The article shows what a daunting task it can be for a researcher to make sense of such a process of transformation, especially amidst the seeming chaos of conflicting voices, dichotomous forces and strong interactions active between the people and aspects within such a situation. Referring to a recently completed study in a rural settlement community, the article concludes that the use of a theoretical framework, such as CHAT, as a heuristic tool, could be valuable in helping researchers make sense of the often complex dynamics of early childhood education development within the specific context of rural community life.
\end{abstract}

Keywords: rural early childhood development (ECD); participatory action research; community education; cultural historical and activity theory.

Sonja van der Vyver, Centre for Education Practice Research, University of Johannesburg. E-mail: iansonja@vodamail.co.za.

South African Journal of Childhood Education | 2012 2(1): 140-158 | ISSN: 2223-7674 | ๑ UJ
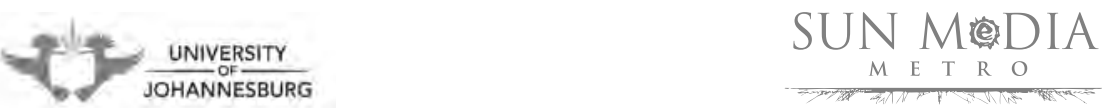


\section{Introduction: ECD last on the agenda of educational transformation?}

Establishing early childhood development (ECD) at rural sites in South Africa is challenging. This is partly because early childhood and education, young children's learning, and curriculum and teacher development do not take place in a void, but within specific contexts where various, and often unexpected, dynamics play a role. These intricate processes involve diverse people, who are influenced by a host of other people and by the beliefs, rules and power structures that hold sway in their specific situations (Sen, 1990). The 'one size fits all' trends in South African educational provisioning and curriculum development, although intended as a means to ensure more equitable access to education for the poor, in many instances effectively exclude the very children it was intended for (Harley \& Wedekind, 2004). Although the funding for schools is formulated according to family income, there is often little evidence of how poor children in marginalised communities benefit specifically. In the light of the effects of globalisation and the contemporary view of education as a commodity (Marginson, 1997; Sen, 2003), it is more important than ever to take note of the local, in trying to see the global. Policy makers, practitioners, and researchers are urged, in this article, to view the provision of education as embedded in the very specific context within which it is being delivered; geographically, socio-culturally, socio-economically, and also politically.

The real situation at rural South African crèches and pre-schools is that of a shortage of just about anything one can mention, which, in most cases, would help to advance the children towards successful school education. Apart from family and parental care, which is assumed children may have, the often overfull centres, with high care-giver to child ratios, need material and human resources, such as stimulating programmes, some learning material and adequately trained practitioners (Grey, 2008). Ngobese (2006) argues that the inability of the often illiterate and poor populations in rural communities to contribute, and the very important part that parents and communities are meant to play in the development and educational progress of their children, exacerbate the challenges of improving rural children's early development and later school performance. Despite recent initiatives by the Department of Basic Education (DBE), early childhood education provision in South Africa remains problematic, with low access, low programme quality and low levels of teacher qualification being just a few of the challenges faced in this field. Notably, ECD provision still relies heavily on volunteers and non-governmental/community-based organisations. Add to this the lack of comprehensive policy around ECD (Biersteker, 2010; Biersteker \& Dawes, 2008; Ngobese, 2006) the long accepted habits and perceptions around child-rearing practices in Africa (Pence \& Marfo, 2008), as well as the question of how to proceed towards a workable and effective way of 'doing' ECD so that children really benefit, and the field becomes a conundrum, which could possibly take so long to solve that the current generation of young children will quite literally 'miss the bus' to a better future.

For the democratic principles in education to truly effect change Maarman (2009) argues, they need to add up to the construction of actual changed realities for learners 
in resource-poor settlements. However, the often challenging interplay between aspects of early childhood education provisioning along with diverse perceptions and expectations of different role players within externally implemented community education interventions, frequently cause tensions. These tensions, if not managed effectively, could diminish the possible benefits of ECD for a community (Van der Vyver, 2012). Pressures brought about by everyday aspects of early childhood education implementation, such as the development of a suitable curriculum, the recruiting and training of teachers, and the day to day functioning and management of a pre-school within the existing power structures of a community, all contribute to the complexity of such a situation. Referring to the community of Mogwase, I argue that the tensions are powerful mechanisms for change, but caution that there is a caveat; researchers and development agents in researcher roles should not only have sound empirical knowledge, but also a strong theoretical framework from which to view the work on an ECD site. I propose this not so much as a view to advance theory as much as a view to understand practice (Henning \& Gravett, 2011) and thus to scaffold research.

On this view, I argue that tensions, as uncomfortable as they might feel to participants, are necessary for the process of education development to evolve and, if managed properly, could even be seen as the main driving force in such a process (Van der Vyver, 2012). For an ECD project, such as the one to which I refer, to succeed it is important that the different voices of the people of the target community, no matter how disparate, be heard so that tension, as a catalyst for change, can be elicited. As Sergiovanni (1994) proposes, schools are about relationships and effective teaching and learning will come about more naturally if schools are viewed first and foremost as communities of different people in dialogue. Add to that the chronology of attention to educational reform since 1994 , and it is clear that primary school, foundation phase and pre-school issues came behind attention to further education and training (FET) and senior phase development programmes. With no public provision for care and education before Grade R, it is reasonable to say that ECD has been the last item on the agenda of transformation of public education and that this, coupled with the role of poverty in education performance, has not bode well for the sector (Van der Berg, 2008).

\section{A research genre and framework for an ECD inquiry}

In a study about an emergent ECD project it will not come as a surprise that participatory action research (PAR) was employed as part of a research strategy. This approach is one way of managing the (empirically) emerging tensions within the process of establishing early childhood education centre in a rural setting. The hallmark of PAR is that it looks for solutions from the people who are the object of the inquiry (Beukema \& Petersen, 2007). Through repeated cycles of planning, action and reflection, a platform is established from which the views of all stakeholders can be aired. This requires the researcher to work empirically while reflecting theoretically. This mode of research and solution-seeking activity could serve as an outlet of often 
strong and conflicting views, and as a forum where opinions are put to the table for discussion and for recording. Simply put, people want and need to be heard when their communities are 'being developed' (Bailur, 2007). And by the same token, researchers need to reflect on this practice (Beukema \& Petersen, 2007) and use new and existing data to do so.

The shortage of data on almost all aspects in the field of ECD delivery in South Africa is cited by Biersteker and Dawes (2008) as one of the critical challenges that need to be addressed. Although some data exist on enrolment and ECD provision by schools, data on provision and processes of development at stand-alone ECD sites are disparate. And to gather such data remains challenging. When conducting research in PAR one has to look for patterns/order in the seeming chaos of tensions that arise amid bouts of reflection, planning and action.

This is when it could be useful to view the data heuristically, from a different vantage point. Applying a thinking tool, such as cultural historical and activity theory (CHAT), could help the researcher retain a specific focus, and make sense of community education research as a process or activity, instead of considering it as a static situation. I opted to use this framework and found it very helpful. Having previously studied classical Vygotskian theory (Kozulin, 1990; Vygotsky, 1986; 1978) I began a process of familiarising myself with newer theories in this tradition. I was attracted to the work of Engeström $(1987 ; 1991 ; 2001)$, because of its appeal to researchers trying to understand social systems and their dynamics. Engeström developed his version of classical Vygotskian cultural historical theory, sometimes also referred to as sociocultural theory and Leontiev's (1978) activity theory, to emphasise the role of tension, and contestation, in what he refers to as an 'activity system'. In doing this Beatty \& Feldman (2009) and Beatty (2012), point out that he thereby subsumed sociocultural (cultural historical) theory and extended 'the (conceptual) triangle' that Vygotsky (Vygotsky, 1978; Kozulin, 1990) used to present his ideas. Vygotsky (1978) proposed that human activity is mediated by tools and signs and that the object of this activity is not acted upon without a host of semiotic indicators, such as language, and other artefacts and tools. One of the main tenets of this more recent theory is its focus on the interconnectedness between all aspects of a social/'activity' system (Beatty \& Feldman, 2009). According to this view of human activity, Engeström (1987) proposes that a systemic perspective on such activity would include different aspects of its context. De Beer and Henning (2011) make the point that the Russian word for activity is not directly translatable into English and that the German translation Tätigkeit ('doingness') explains the notion of on-going engagement in a programme of action towards a specific objective, with a specific motivation, and envisaging a specific outcome.

Thus, in the heuristic of an activity system, and thinking of its various nodes (cf. Figure 1), the acting/engaging subject, which is the person or group whose actions the researcher is seeking to understand, uses tools, such as computers, language (a signing tool), and a curriculum, to move towards the object of the activity and, in doing so, to (hopefully) produce certain outcomes. The action of the subject is, however, not taking 
place in isolation; it is impacted upon by the community, which represents the other stakeholders in the object of the activity. The division of labour within a community also impacts on the action of the subject. It has to do with how tasks are allocated within the community and how the community is stratified around structures of power and status. Coupled with that is rules, which include those regulations, conventions and beliefs valued by the community, and that influence the actions of the subject, its choice of tools, the extent to which it adheres to the notions of the division of labour and its interaction with the community, and so forth. However, as Beatty and Feldman (2009: 18) caution, describing an activity system in isolation is pointless. To understand some of the tensions in a social system where a specific activity is investigated, it too, has to be seen in a wider, systemic context and in an historical gaze. There is, thus, a need for what researchers refer to as a "thick description" (Geertz, 1973: 7 in Ryle, 1949) of the system. The aim of this article is to present such a description of one system and its tensions. The work is thus conceptual and the heuristic device remains no more than an analytical tool. It does not aim to classify empirical reality of the PAR process, but to understand it a little better.

In the thick description of the process of establishing an ECD site at a rural informal settlement, I will first describe the organic nature of such a process, the various tensions that could arise between the different role players as a result of the process, and, briefly, also how these can be managed in PAR mode. I will then show how the application of a heuristic tool, such as the notion of an activity system, can be employed during research to make sense of the seeming chaos of such a process and to give the empirically thick description some theoretical explanation (Geertz, 1973).

\section{Education research in a development context: Moving beyond technical evaluation}

This study emanated from social development work in a rural informal settlement in a province in South Africa. The work comprised development in a village settlement and included most aspects of daily living of its 700 inhabitants. Although informal settlements are common around cities and towns, new rural settlements are less common. The changes in everyday village life are not unusual and in this instance, nothing extraordinary took place, except that a pre-school ${ }^{1}$ was established, unexpectedly, by the donation of two shipment containers ('edutainers'). From this, then, a whole new programme of lay teacher development was created and a new curriculum was forged for the emergent pre-school and for the teachers as well.

The project started with only some realisation of the many interrelated factors that challenge the linearity of a simple input-output view of ECD and education in a country like South Africa. There are, for one, different strategic links between public sector departments, such as public health and social development and also basic education. This is, possibly, why the ECD sector was included in the Human Resources Development Report for the first time in 2008 (Biersteker \& Dawes, 2008). The authors, who wrote the section on ECD for that document, contend that this indicates 
the extent to which the South African government has realised just how essential ECD is for laying the foundation for success in the schooling system and how important it is to introduce, especially those children who come from poor environments, to quality ECD provision.

Prior to the report by Biersteker and Dawes (ibid), there had been some policy development. These authors state that the White Paper (1995) marked the beginning of growing support for ECD as the actual start to the educational journey for the post-apartheid education authorities. The South African Congress for Early Childhood Development (2011), a representative body of national non-government organisations that aims to organise, mobilise and unify the early childhood sector in the country, included 'research' and 'policy development' as part of its founding aims. This growing focus has highlighted the need for sound education research in the sector. As argued by Biersteker and Dawes (2008) and later also by Biersteker (2010), it is imperative to build knowledge directly from 'the ground' to add to our understanding of how communities, donor agencies, development practitioners and the public service can collaborate to care for and prepare young children for school. The shortage of data on almost all aspects in the field of ECD provision in South Africa is cited by Biersteker and Dawes (2008) as one of the critical challenges that need to be addressed. Although some data exist on enrolment and ECD provision by schools, data on provision at stand-alone ECD sites are scarce and also disparate. The recently established South African Research Association for Early Childhood Education (SARAECE), founded by researchers in this field to drive research that goes well beyond project evaluation and mere surveys of sites, is one move in the direction of systematic, co-ordinated research in the field.

There is also a need for sound academic evaluation research that is grounded in theory and that moves beyond output measures. Historically, in South Africa, project evaluation is aimed at showing how well a project is aligned with the aims and objectives set for it by the funding agent and is not conducted from a theoretical position Christie (2003), in a study on the "practice-theory relationship" in evaluation, found that only $36 \%$ of studies had a theoretical grounding. In edited volumes of a series, "New Directions for Evaluation" the American Evaluation Association aimed to address this issue. Two of these edited volumes by Stufflebeam (2001), and Caracelli and Preskill (2000) explore the topic further.

Working from a specific theoretical perspective gives a researcher a structured framework from which to assess and interpret the unpredictability and seeming chaos that often characterises the organic process of community education delivery. It is, therefore, important that the researcher acknowledges the various tensions that emerge from the community's 'becoming' in a Deleuzian (cf. Semetsky, 2006) sense. Equally important, and perhaps advisable, is that a researcher brings order to this seeming entropy, at least heuristically, through employing a theoretical framework as organising principle (Christie, 2003). In my own venture into the community of 
Mogwase I learned the value of a stable theoretical framework when I entered the maze of community development.

\section{Mogwase ${ }^{2}$ - a community 'becoming'}

Mogwase is an informal rural settlement situated 15 kilometres from a small town on the edge of the Gauteng Province of South Africa. The land for the settlement was secured, with the help of local government, by 55 members of the community in 2001. The community thus owns the land, and the settlement is governed, at community level, by a steering committee, and, on a larger scale, by the local regional council. A councillor for the region, appointed by the African National Congress (ANC) serves as link between the steering committee and regional government.

Prior to the introduction of the Extension of Security of Tenure Act (No. 62 of 1997), agricultural workers in the area were extremely vulnerable and often displaced when the land they had been working on changed ownership, or when the nature of the agricultural activity they had been working in changed in such a way that they were no longer employed. The nature of economic pursuits within the area had been changing from pure agriculture to eco-tourism and recreation. Also, where agriculture remains, the mechanisation of farming activities rendered the employment of many unskilled labourers redundant. Many of these displaced unskilled labourers settled at Mogwase in 2000.

\section{First a windmill and then 'crèche-ing' at Mogwase}

The Mogwase community development project was initiated at the end of January 2008. Through participatory methods, such as transect walks, informal discussions with members of the community, group discussions and the exploration of case studies described by the people of the new community (Binns, Hill \& Nel, 1997), the settlement's most urgent expressed needs (Werner \& Bower, 1983: 3) were explored. Discussions with individuals and small groups all pointed to the lack of a constant source of clean drinking water as their most pressing need. However, the legacy of several failed projects that had been implemented by the local government meant that the people of the settlement were very distrustful of outsiders. After careful deliberation, the development practitioners and the community steering committee submitted a proposal to a large corporate funder and succeeded in securing a windmill for the settlement. Although the proposal was accepted, a long process involving months of waiting for paperwork to be finalised ensued. Thus, when, after a long waiting period, the windmill was finally erected in November 2009, it served to instantly unify the people and to bring them to implicitly trust the development practitioners as allies.

Shortly after the erection of the windmill the development practitioners were then approached by a corporate social investment (CSI) manager from an affiliate to the existing corporate funder. She enquired about the status of ECD provisioning in the village $^{3}$ and wanted to know whether Mogwase needed a crèche. It turned out that 
this prospective funder could assist with the provisioning of an edutainer, which is a shipment container that had been converted to a classroom and which could serve as the location from which an ECD programme could be developed.

Knowing that no need for ECD had been expressed up to that point by the community, but not wanting to pass up on the opportunity to secure the resources for an ECD project, the development practitioners decided on a campaign to create awareness about ECD in the community. After a very short time, during which the village inhabitants were made more aware of the possible benefits an ECD facility would bring to the community, they unanimously agreed that the edutainers would be a good idea.

\section{Tensions arise and participatory action research (PAR) begins}

Prompted by the unexpected offer of sponsored ECD provisioning for the community, the development practitioners had, in this one instance, veered away from the peoplecentred approach, which they had followed up to that point. From this divergence, then, a rather intense and disorderly process of curriculum development and teacher training started. The situation became at times rather chaotic and even volatile as tensions mounted around the crèche, and how it should be implemented at the settlement. Three volunteer mothers started to work at the crèche. As the now designated educational development practitioner, I envisaged the crèche at Mogwase as an entity grown 'by the community for the community'. I hoped for these young women to be given the chance to 'work out' a suitable curriculum for the crèche, by combining their new resources (the edutainers, playground equipment, educational toys and equipment) with their existing indigenous knowledge of ECD. However, this approach resulted in conflict and tension as the teachers acted according to the community's belief that children should be in the crèche to be 'kept safe', and that the volunteers would act in a child-minding capacity and no more. However, the parents demanded that the teachers 'teach' their young children to read and write. Also, the volunteer teachers earned a stipend, which, however small it was, constituted a sizable income in a community where only ten percent of people earned any money ${ }^{4}$. This elevated them to the status of 'top-earners' in the settlement. These three young women were catapulted into a position of stark opposition to many of the community's beliefs about young women and their place in that small society. For instance, in Mogwase, young woman have very little status, and grandmothers have the ultimate say over what happens to the children of these mothers.

This 'failure' of the lay practitioners to 'invent' a suitable curriculum led to the suggestion, by the development practitioners (including myself) and the village committee, that the volunteer teachers needed professional training. As a fluent Setswana speaker I was tasked to start training the teachers, once a week, in the basic principles of ECD, and arranged for them to attend a nearby pre-school once a week to gain some on-the-job experience. This second intervention proved inadequate to address what the community perceived as their children's early learning needs. 
Conflict arose between parents and teachers, as well as the committee and the development agents, as a result of the many opposing views and expectations of what ECD should entail in the settlement. Two incidents of physical violence between parents and teachers resulted in the crèche closing down for two weeks, during which all stakeholders carefully reflected on the situation. It was then decided, collaboratively, that the volunteer teachers needed intensive, day-by-day training, not by a development practitioner, such as myself, but by an external trainer. This proved to be the very thing that was needed for the situation to progress and over a period of a little over a year, the teachers, in collaboration with their trainer, Paulina, and with the input from the parents and the community committee, managed to forge a context-specific curriculum at the site.

\section{Activity theory as a lens for viewing the Mogwase crèche development}

What had been happening during this time was, in effect, the first phase of a PAR project. To try and understand the systemic dynamic, I utilised CHAT as theoretical framework in a study of the founding of the pre-school to serve as a theoretical gaze, while the PAR developed empirically.

The successful development of an organic curriculum and the training of the teachers at this site were reflected in a number of findings from the study. The main finding was that, despite the many challenges of implementing a society-initiated ECD intervention in a rural community with untrained teachers, it is indeed possible for the community to come to own the intervention. It was also possible for a context-true curriculum to develop organically, with young children using their school tools and the village tools, such as the vegetable gardens and the water reticulation works as learning materials, for example. And for the teachers, there was now the opportunity to progress towards their own professional development in the field of ECD.

Furthermore, the study shows that tensions arising from the implementation of such an intervention, if managed in PAR mode, could provide the necessary impetus for participants to actively look for solutions to the practical problems they face and to facilitate a shift in their paradigm, from one of scarcity, child minding and discord to one of expanded awareness that combines their indigenous knowledge of traditional child care with more systemic concepts of early childhood education and school preparation.

I will now show how I used Beatty and Feldman's (2009) interpretation of Engeström's model. I will also show what role the tensions that operated between the different role players and aspects of this intervention played when looking heuristically at the interaction between the different nodes of the activity system. 


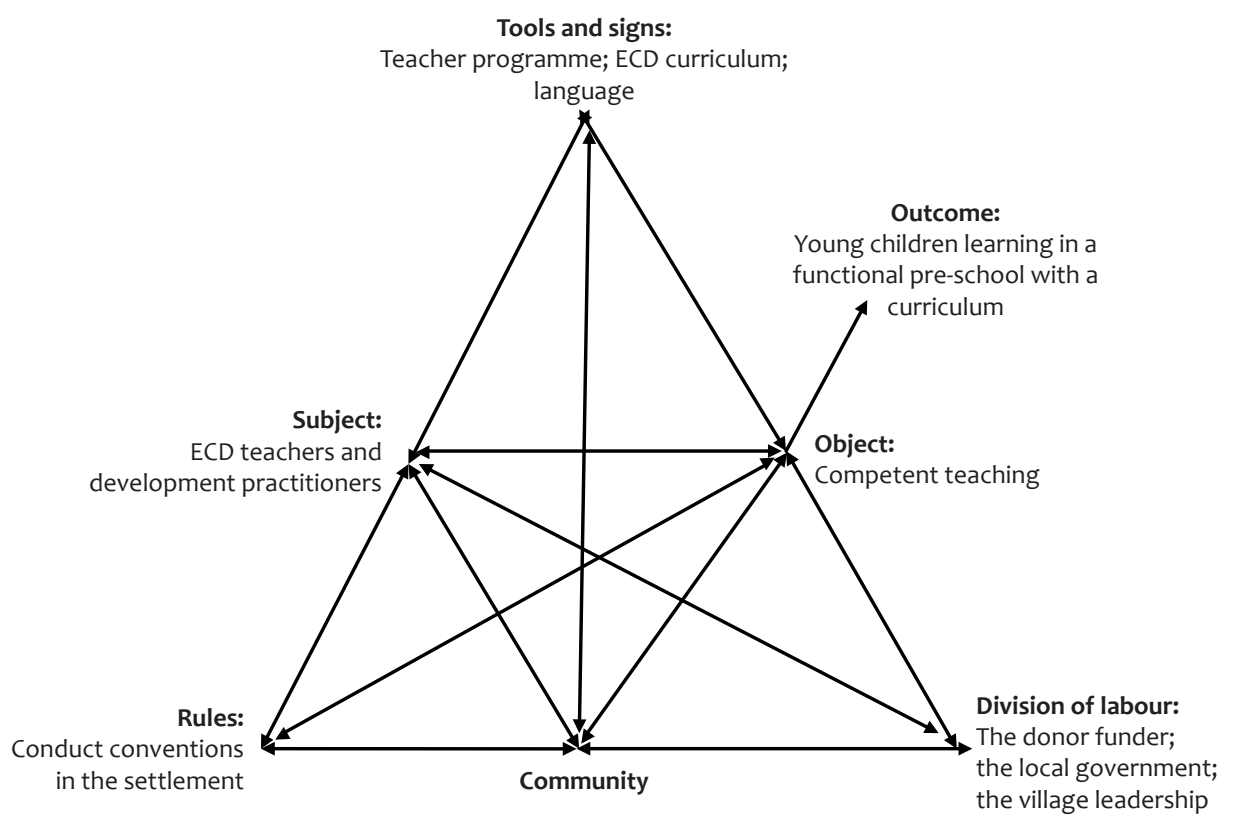

Figure 1: Relationships between elements of an activity system: the emergent Mogwase ECD project (adapted from, Engeström, 1987).

According to Engeström's model of an activity system (2001, in Beatty \& Feldman, 2009), the subject in the activity system is described as the viewpoint of analysis or as the person or sub-group whose actions we seek to understand. The group of volunteer ECD teachers and the development practitioners engaged in the activity of establishing and running the crèche, comprise the unit of analysis within this activity system. They can be seen as the "point of view" of the study or the "person or group whose actions we seek to understand" (ibid: 4).

The object, that which 'motivates' the actions of the subject and 'upon' which the action is lodged, is the professional development of the volunteer teachers. The outcome of the subject's acting on the object, of the volunteer teachers undergoing a process of professional development, is the generation of an organic curriculum (within the context of teacher development). The outcome includes the dimension of children who are cared for and who may be ready to enter formal education after they have 'graduated' from the crèche.

The subject in an activity system makes use of artefacts/tools to act upon the object in order to bring about the desired outcomes. The tools are 'mediational means', and they are inherently semiotic, carrying the norms and signs of the culture, especially as these are embodied in language. These tools can be physical, such as the edutainers and outside play equipment. They can also be cognitive, as in the case of new teaching methods and new professional habits that have been formed. Symbolic tools (signs) 
used by the teachers include language and how it is used in the classroom, discourses, pictures, and a curriculum, which is one of the main tools of educational settings, such as this ECD setting.

The notion of community refers to the participants who are engaged in the collective activity with the subject, together with other stakeholders in the object of the activity. The committee, parents, leaders, donor funders, development practitioners, trainers and members of local government all have an interest in the development of ECD within this settlement. They can be said to make up the community within this system. I mentioned, already, that the term activity does not refer to a single act or action, but to the notion of collective 'doingness'.

The concept of a division of labour within activity systems has a horizontal and vertical component to it. The horizontal division of labour refers to how and by whom certain tasks are carried out in the community, while the vertical division of labour refers to how relationships of power and status are perceived by the members of the community (Centre for Activity Theory and Development Work Research, 2003, in Beatty \& Feldman, 2009). This refers to the management and the hierarchical relations within the community. In this case, the relatively low status of young mothers, as perceived by the community, could be said to be an example of both the horizontal and the vertical division of labour in the settlement. The role of young mothers in this settlement is to take care of their children and to assist their own mothers with household chores. When young mothers suddenly become 'teachers', and moreover 'well paid' teachers, their status is disproportionally elevated, in the view of the community. This causes disequilibrium in the system of which the teachers are part and challenges the existing relationships of power and status.

The rules in an activity system can be 'implicit' or unexpressed, such as traditional customs and beliefs, or 'explicit' and stated in detail such as policies, laws and regulations. Either way rules shape the behaviour of community members (Beatty \& Feldman, 2009). Examples of explicit rules within the activity system of the crèche at Mogwase include rules made by the committee to regulate behaviour within the settlement, the rules of the donor funders regarding expenditure and government policy around the regulation of ECD sites in Gauteng. Implicit rules include beliefs around gender equity, capabilities of young women to look after children, and what constitutes acceptable ECD practice in Mogwase.

\section{Principles of activity theory in action: The tensions within the 'activity system' of a new pre-school}

Engeström and others felt that second-generation activity theory, the iteration after Leontiev's version of activity theory (Leontiev, 1978), failed to present the interconnectedness of the different aspects or to "understand dialogue, multiple perspectives, and networking's of individual activity systems" (Engeström, 2001: 135). In using this perspective on the work of a small system in society I found a stable theoretical position from which to observe what I had been experiencing in the harsh 
empirical reality of the PAR project, and in which I had become a researcher, after having become a participant by default, due to the donation of the edutainers. I utilised the five main tenets or principles (of this take on activity theory) as heuristic with which to process the development of the crèche project as a scholar of educational development.

The first principle is that "a collective artefact-mediated and objects-orientated activity system, seen in its network relations to other activity systems, is taken as the prime unit of analysis" (Engeström, 2001: 135). This is an important distinction and it comes from classical Vygotskian theory, in which mediated activity is the unit of analysis (Wertsch, 1990). With Engeström's view, it logically holds that the whole system would be the unit of analysis. And so it was in this project too, that "goal directed individual and group actions" (Engeström, 2001 in Beatty \& Feldman, 2009: 4), the actions towards the implementation of the ECD facility and practitioner training in Mogwase, "are relatively independent, but subordinate units of analysis (and that) are eventually understandable only when interpreted against the background of an entire activity system" (ibid). In Mogwase for example, the training experiences of the volunteer practitioners as individuals, and as a group, cannot be viewed apart from the expectations and evaluation of the parents, the community committee, the donor funders, the development practitioners, the trainers or local government authorities. Some would argue that this view of activity is radically systemic and I would concur. But such a theoretical view on a rural informal settlement community's enterprise helped to clear the air in trying to understand the PAR reality.

The second principle deals with "the multi-voicedness" of activity systems. An activity system always comprises a community of multiple points of view, traditions and interests (ibid: 5 ). It is evident that in the situation in this study there are indeed vastly different points of view with regard to what constitutes quality ECD practice from the multiplicity of stakeholders in this study. Traditional beliefs and customs around early childhood education and care are standpoints that play an important role within the activity of this system. Lodged within these points of view are, not unexpectedly, multiple tensions. For the somewhat perturbed PAR researcher this was some consolation.

The third principle is 'historicity'. Activity systems evolve over "lengthy periods of time. Their problems and potentials can only be understood against their own history" (ibid). I list here a few of the historical aspects that affect the activity system in this study. The establishment of the village where the pre-school is situated came about due to the settlement there of 55 farm workers and their families, as a result of their displacement by farmers in the area from agricultural land in response to The Extension of Security of Tenure Act (1997). The land on which the village is situated was then purchased by government on behalf of the residents. Conflict about leadership and other political issues have often flared up leading to poor internal cohesion in this community. The larger community development project, of which the crèche forms part, is another historical factor that impacts on the 'system' of the crèche. Events 
which transpired before the establishment of the crèche; for example, how the larger project transpired before the establishment of the crèche play a role in perceptions and expectations of the crèche by the different role players; development practitioners, community members, committee members etc., even before the crèche opened its doors for the first time. For example, how the community viewed the authority and trustworthiness of the development agents played a determining role in their decision to accept the donation of the edutainers in the first place.

The fourth principle is "the central role of contradictions as sources of change and development" (Engeström, 2001 in Beatty \& Feldman, 2009: 5). According to Engeström (ibid), contradictions cannot be equated with "problems or conflicts". This is an important distinction. He suggests that these are "structural tensions within and between activity systems", which "accumulate historically" and which not only "generate disturbances and conflicts", but also include "innovative attempts to change the activity". An example of this, taken from the pre-design, or the exploratory phase of the study, would be the contradiction between the traditional beliefs around early childhood care and education and notions, held by members of the community, of what ECD in a contemporary 'crèche' set-up should involve. These and other contradictions are some of the major dynamics that played a role in the evolvement of the crèche intervention.

The fifth principle states that the possibility exists for "expansive transformation in activity systems" (ibid) and proposes that "activity systems move through relatively long cycles of qualitative transformations" through which the contradictions of the system intensify. This intensification to "aggravation" causes some individual role players to "begin to question and deviate" from the "established norms" of the activity system (ibid). According to Engeström (ibid) "an expansive transformation is accomplished" when the object and motive of the activity are "reconceptualised" so that a vastly larger array of possibilities is accepted than what was the case in "previous mode of the activity". An example of such transformations within the activity of establishing the crèche at Mogwase include the transcending, by the teachers, of the discourse of scarcity and child-minding that was prevalent in the community when the crèche first started, to a discourse that reflect their professional growth as teachers. Another example would be the growing collaboration between role players on matters affecting the crèche and the growing political agency of the teachers to take part in the decision-making processes that affect their work. As the project progressed there was evidence of changes in perception by parents and members of the steering committee of teachers' ability to take care of, and educate, young children, and of the educational benefits that the crèche brought to the community and, ultimately, the community's ownership of an externally initiated intervention.

As can be seen from the discussion of the components of what constitutes, heuristically, the activity system of the crèche at Mogwase, multiple tensions can be said to exist and are generated by the so-called 'activity' between the different 'nodes' within the system. In saying this I emphasise that 'seeing' these nodes is a heuristic 
act, not a classificatory one in any empirical sense (Wardekker, 2008). This means that the conceptual gaze I exercise as a researcher is merely to understand some of the empirical vastness that I see into some patterned/ordered structure. It does not mean that there are empirical instantiations of what I contemplate conceptually. This distinction is often missed in literal applications of theories in education.

Taking the training volunteer teachers as the subject, they can be seen, clearly, at one level, as the focus point for all the activities that take place within the system. Whether or not, and to what extent, the object or outcome of the system is met, depends on the teachers and how they choose to employ the tools at their disposal. It is up to them, for example, to choose which language of instruction they will employ in their teaching practice. Therefore, implicit in their choice and use of the tools exist some tension. They have, on the one hand, the power to make or break the process of achievement, if at all, of the emergent curriculum, and on the other hand they are subject to the influences of all other components of the system. For example, although the community in this instance is challenged by the teachers' new role, to revise their existing view of the rules that hold sway and the accepted division of labour within the community, the tensions that result from this interaction between community, rules and the division of labour is projected by the community onto the teachers, thus influencing, and putting under strain, their actions towards the object.

As already mentioned the development of this pre-school took place in PAR mode, which meant that the teachers could participate, albeit at first from a position of relatively little power, increasingly with more authority, in the process of implementation of the pre-school and its curriculum. As they negotiated their position with regard to the other role players and as they became more assertive in their roles, they gained a greater sense of agency in their own professional lives. As parents' knowledge of ECD and of the role the ECD teacher plays in the development of young children increased through the parent orientation programme, the pressure on the teachers also eased off a bit.

\section{Conclusion: Where theory and participatory research meet}

I draw a number of conclusions about theory and research in the type of context typified in Mogwase. Firstly, although the views of the different role players in the ECD intervention in this study were often extremely conflicting, their participation in the process of finding better ways to implement the crèche seems to have been the only way for the situation to progress. PAR, by its very nature, is not necessarily a smooth process, but one that is often fraught with tension that causes it to progress, not in linear fashion, but in a cyclical way (Reed, 2004). In a sense, conducting this research in PAR mode created the conditions and 'space' for dialogue to take place. In this shared space all the interrelated parts of the school community could participate in the implementation of the pre-school and the development of the curriculum, however haphazard some of the processes proved to be. Indeed, the voice of Ngobese (2006) rings true: the early development of children and the effectiveness 
with which early childhood education interventions are implemented and conducted in rural settlements depends on a community's understanding and support. This understanding and support, I would argue, relies, in turn, on the extent to which all stakeholders are encouraged to voice their concerns and opinions about the crèche, and on the researcher's ability to maintain a clear view of the situation. Charting the dialogical nature of research conducted in PAR mode, with the help of a theoretical gaze, such as CHAT, can help the researcher gain more clarity on the different dynamics and processes at play in the vortex of research that is coupled with development.

Secondly, in this study it was once more affirmed that the unitary view of community, a notion which is often employed by outsiders, such as development agents (Skogen \& Krange, 2003), ignores the existing social stratifications, alliances and power structures within a community (Cleaver, 1999) and assumes a generic 'community' phenomenon that is nearly impossible to find in the real world of the twenty-first century. The complex dynamics of the causes and effects of poverty on the ability of the community to understand support and assist children's learning also intricately, and powerfully, impact on the success of ECD delivery at rural sites. Once again, applying CHAT as a lens through which to 'gaze' upon the situation in a study could clarify the various interactions between the more complex aspects of the system, such as the division of labour, to understand, for example, the social stratification, status and constructs of power within a community for the researcher. To this study the theoretical frame brought some rationality to a researchers' participation.

The third conclusion that I have come to is about the notion of national policy in a country with such a prominent Gini index. A national policy is by virtue an aggregation with a number of contextual exceptions. This, I find somewhat fallacious. A national curriculum and standards for assessment are noble, modernistic ideals. However, together with Cross, Mungadi and Rouhani (2002), I would argue for a realistic and pragmatic approach to early childhood education and concomitant education research - one that would focus clearly on the specific circumstances within which it is to be implemented or conducted, especially at rural sites, which differ geographically and socio-culturally. Most of the circumstances that impact negatively on the effectiveness of rural early childhood education delivery manifest at the nebulous intersect between 'underdeveloped rural settlement' and 'poverty'. A lack of infrastructure, low education and skills levels, unemployment, gender inequity and the effects of the HIV/ Aids epidemic on the family lives of children are just a few of the factors which impact on the daily lives of the poor living in underdeveloped rural settlements, where, like in Mogwase, their first urgent need was simply water. It is precisely this dynamic that requires attention and research in order to fully understand the context of the ECD sites in rural settlements. Through the application of a theoretical framework, such as CHAT, this interplay within an 'activity system' was clear. I did not venture to related and larger activity systems to which this small part of the South African reality can be jig-sawed, and to which, heuristically early childhood education at a rural site can connect right up to the Presidency. 
I also conclude, fourthly, that conducting research at rural ECD sites is a daunting task, especially if it goes beyond technical evaluation studies (cf. Caracelli \& Preskill [2003: 1], who ask for "a reconceptualisation of evaluation use that reflects the diversified and changing landscape of the evaluation discipline.") However, if one views the forging of a crèche as an activity that takes place at a certain place at a specific time and embedded in a particular way of life then the seeming chaos could be perceived as a thrust by the members of a community towards greater autonomy. What seems like disorder then becomes a reflection of a people striving towards being able to provide for its own education needs. In short, if the researcher takes the dynamic system of the entire activity as the unit of analysis that is being investigated it might render the more contradictory and confusing components of the situation more manageable.

Lastly, I conclude that life in a rural settlement, although not reflected in Western education literature as constituting the typical background from which pre-school children come, is still life for many people. Sound, in-depth research and not just surface-deep evaluation of education development at rural sites is needed if we are to truly address the early education needs of young children from resource-poor rural contexts. I would argue that PAR is an essential component of research into reallife situations and that a theoretical framework such as CHAT could be effectively applied as an important organising principle to help the researcher see the patterns and the order within the seeming chaos that is simply the symptom of a community 'becoming'.

\section{Acknowledgements}

In the second phase of the study that is reported in this article, I conducted a study towards an MEd degree and I was a bursary holder in the DHET/EU Programme of Research at the University of Johannesburg.

I wish to thank Dr Nadine Petersen and Prof. Elbie Henning, supervisors of the study, for their help in writing this article.

\section{Endnotes}

1. In colloquial discourse the term 'crèche' refers to a facility where children are looked after and where pre-school activities take place. I therefore use the terms 'crèche' and 'preschool' interchangeably in the study.

2. All names of people and placed have been changed for ethics reasons.

3. There was, up to that point no early childhood education site accessible by the children from the settlement. The closest primary school, offering Grade R, was three kilometres away too far for pre-school children to walk to - and back every day.

4. This is apart from child support grants that are given to low-income mothers of children under 16 years in South Africa. 


\section{References}

Bailur, S. (2007). The complexities of community participation in ICT for development projects: The case of 'our voices'. Proceedings of the $9^{\text {th }}$ international conference on Social Implications of Computers in Developing Countries, May 2007, Sāo Paulo, Brazil. [Online.] Available from: http://www.ifipwg94.org.br/fullpapers/ Ro010-1.pdf.

Beatty, I. D. (2012) (forthcoming). Seeing teacher development from an 'activity system' perspective. Education as Change, 17(2).

Beatty, I. D. \& Feldman, A. (2009). Illuminating teacher change and professional development with CHAT. Proceedings of the NARST Annual Meeting, April 17-19, Garden Grove, CA, United States.

Beukema, L. \& Peterson, N. (2007). Participatory action research. Presentation to SANPAD Cohort.

Biersteker, L. (2010). Scaling-up early child development in South Africa. Introducing a reception year (Grade $R$ ) for children aged five years as the first year of schooling. Wolfensohn Centre for Development. Working paper 17, April. Washington DC: Brookings Institution Press.

Biersteker, L. \& Dawes, A. (2008). Early childhood development. In: A. Kraak \& K. Press (eds.), Human Resources Development Review. Cape Town: HSRC PRESS.

Binns, T., Hill, T. \& Nel, E. (1997). Learning from the people - Participatory rural appraisal, geography and rural development in the 'new' South Africa. Applied Geography, 17(1): 1-9.

Caracelli, V. J. \& Preskill, H. (2000). Editor's notes. The Expanding Scope of Evaluation Use, 88: 1-4.

Christie, C. A. (2003). What guides evaluation practice maps onto evaluation theory. The Practice-Theory Relationship in Evaluation, 97(1): 7-35.

Cleaver, F. (1999). Paradoxes of participation: Questioning participatory approached to development. Journal of International Development, 11: 597-612.

Cross, M. Mungadi, R. \& Rouhani, S. (2002). From policy to practice: Curriculum reform in South African education. Comparative Education, 38(2): 171-187.

De Beer, J. \& Henning, E. (2011). Retreating to a Vygotskian stage, where pre-service teachers play out social, 'dramatical collisions'. Acta Academica, 43(3): 203-228.

Engeström, Y. (2001). Expansive learning at work: Toward an activity theoretical reconceptualization. Journal of Education and Work, 14(1): 133-156.

Engeström, Y. (1991). Activity theory and individual and social transformation. Activity Theory 7(8): 6-17.

Engeström, Y. (1987). Learning by expanding: An activity-theoretical approach to developmental research. [Online.] Available from: http://lchc.ucsd.edu/MCA/ Paper/Engestrom/expanding/toc.htm. (Accessed 1 March 2009.) 
Extension of Security of Tenure Act (No. 62 of 1997). Government Gazette 389, No. 18467.

Geertz, C. (1973). Thick description: Toward an interpretive theory of culture. In: C. Geertz (ed.), The interpretation of cultures. New York: Basic Books.

Grey. M. J. (2008). An investigation of the programmes and equipment used by caregivers and day mothers for the age group 0-36 months in the Limpopo Province, South Africa. Published MA thesis, Wits University. Johannesburg, South Africa. [Online.] Available from: http://wiredspace.wits.ac.za/bitstream/handle/10539/4800/Marga \%20FINAL\%209-06\%20Ch\%201\%20-\%207(dees\%20Version).pdf?sequence $=4$. (Accessed 12 November 2011.)

Harley, K. \& Wedekind, V. (2004). Political change, curriculum change and social formation, 1990 to 2002. In: M. Nkomo, C. McKinney \& L. Chisholm (eds.), Changing class: Education and social change in post-apartheid South Africa. Human Science Research Council. HSRC Press, pp. 195-220.

Henning, E. \& Gravett, S. (2011). Pedagogical craft and its science: Janus faced in preservice teacher education. Education as Change, 15(S1): 21-33.

Kozulin, A. (1990). Vygotsky's psychology. A biography of ideas. Cambridge: Harvard University Press.

Leontiev, A. (1978). Activity, consciousness and personality. Englewood Cliffs: Prentice-Hall.

Maarman, R. (2009). Manifestations of 'capabilities poverty' with learners attending informal settlement schools. South African Journal of Education, 29(2009): 317-331.

Marginson, S. (1997). Markets in education. [Abstract]. St. Leonards: Allen \& Unwin.

Ngobese, Z. X. (2006). Exploring the problems of teachers and their teaching in farm schools. Unpublished MA thesis, University of Johannesburg, Johannesburg, South Africa.

Pence, A. R. \& Marfo, K. (2008). Early childhood development in Africa: Interrogating constraints of prevailing knowledge bases. International Journal of Psychology, 2008(i): 1-10.

Reed, J. (2004). Using action research in nursing practice with older people: Democratizing knowledge. Journal of Clinical Nursing, 14: 594-600.

Semetsky, I. (2006). Deleuze, education and becoming. Rotterdam: Sense Publishers.

Sergiovanni, T. (1994). Building communities in schools. [Abstract]. Harvard Educational Review. Winter 1996. [Online.] Available from: http://www.hepg.org/her/ abstract $/ 25 /$.

Sen, A. (2003). Humanity, security and educational gaps. Conference proceedings at the Conference Commonwealth Education Ministers, Edinburgh, Scotland.

Sen, A. (1990). Development as capability expansion. In: K. Griffin \& J. Knight (eds.), Human development and the international development strategy for the $1990 \mathrm{~s}$. London: Macmillan. 
Skogen, K. \& Krange, O. (2003). A wolf at the gate: the anti-carnivore alliance and the symbolic construction of community. Sociologia Ruralis, 43(3): 309-325.

South African Congress for Early Childhood Development. (2011). Profile. [Online.] Available from: http://www.sacecd.co.za/index.php?option=com_content\&view $=$ article $\&$ id $=2 \&$ Itemid $=4$.

Stufflebeam, D. L. (2001). Evaluation Models. Evaluation Models, 89: 8-91.

Van Der Berg, S. (2008). How effective are poor schools? Poverty and educational outcomes in South Africa. Discussion paper for the Centre for European Governance and Economic Development Research, Georg August Universität, Göttingen, Studies in Educational Evaluation, 34(3): 145-154.

Van der Vyver, S. (2012). An early childhood development programme in a rural settlement community. Unpublished MA thesis, University of Johannesburg, Johannesburg, South Africa.

Vygotsky, L. (1986). Thought and language (edited and revised by A. Kozulin) ( $6^{\text {th }}$ ed.). Cambridge, MA: MIT Press.

Vygotsky, L. (1978/1934). Mind in society. The development of higher psychological processes. M. Cole, V. John Steiner, S. Scribner \& E. Souberman (eds. \& transl.). Cambridge, MA: Harvard University Press.

Wardekker, W. (2008). African perspectives of cultural-historical and activity theory. Discussant of symposium at the tri-annual conference of the International Society for Cultural and Activity Research, San Diego CA, 8-12 September.

Werner, D. \& Bower, B. (1983). Helping Health Workers Learn. Palo Alto, CA: The Hesperian Foundation.

Wertsch, J. V. (1991). Voices of the mind. A sociocultural approach to mediated action. Cambridge, MA: Harvard University Press. 